\title{
Effects of copper in Daphnia are modulated by nanosized titanium dioxide and natural organic matter: what is the impact of aging duration?
}

\author{
Rajdeep Roy ${ }^{1} \cdot$ Simon Lüderwald ${ }^{1} \cdot$ Asawer Alawi Ahmed Maknoon ${ }^{1} \cdot$ George Metreveli $^{1} \cdot$ Ralf Schulz $^{1}$ • \\ Mirco Bundschuh ${ }^{1,2}$
}

Received: 1 February 2020 / Accepted: 6 November 2020 / Published online: 17 November 2020

(C) The Author(s) 2020

\begin{abstract}
During its aquatic life cycle, nanosized titanium dioxide $\left(\mathrm{nTiO}_{2}\right)$ may interact with natural organic matter (NOM) ultimately altering the ecotoxicity of co-occurring chemical stressors such as heavy metals (e.g. copper $(\mathrm{Cu})$ ). In this context, the following hypotheses were tested: (1) aging of $\mathrm{nTiO}_{2}$ along with $\mathrm{Cu}$ reduces $\mathrm{Cu}$ toxicity, (2) $\mathrm{nTiO}_{2}$ agglomerates have a lower potential to reduce $\mathrm{Cu}$ toxicity and (3) aging of $\mathrm{nTiO}_{2}$ in presence of $\mathrm{NOM}$ reduces $\mathrm{Cu}$ toxicity further. A multifactorial test design crossing three $\mathrm{nTiO}_{2}$ levels $(0.0,0.6$ and $3.0 \mathrm{mg} / \mathrm{L})$ with two levels of NOM (0 versus $8 \mathrm{mg}$ total organic carbon $\left.(\mathrm{TOC}) / \mathrm{L}\right)$ and seven nominal $\mathrm{Cu}$ concentrations (ranging from 0 to $1536 \mu \mathrm{g} / \mathrm{L}$ ) aged in ASTM medium for 0, 1, 3 and 6 days was realised, while two aging scenarios were applied (type $1: \mathrm{nTiO}_{2}$ jointly aged with $\mathrm{Cu}$; type $2: \mathrm{Cu}$ added after $\mathrm{nTiO}_{2}$ aging). Subsequently, $\mathrm{Cu}$ toxicity was assessed using the immobility of Daphnia magna after $48 \mathrm{~h}$ of exposure as response variable. The experiments revealed that neither aging duration nor the extent of agglomeration (type 1 vs. type 2 aging) has a substantial impact on Cu induced toxicity. Moreover, it was confirmed that the presence of NOM substantially reduced $\mathrm{Cu}$ induced toxicity, independent of the aging scenario and duration. More importantly, the data suggest the ingestion of $\mathrm{Cu}$ loaded $\mathrm{nTiO}_{2}$ as additional exposure pathway contributing to $\mathrm{Cu}$ toxicity. In conclusion, it seems unlikely that $\mathrm{nTiO}_{2}$ concentrations currently detected in or predicted for aquatic ecosystems, which are at least one order of magnitude below the concentration tested here, influence Cu toxicity meaningfully.
\end{abstract}

Keywords Aging $\cdot$ Nanomaterials $\cdot$ Natural organic matter $\cdot$ Metal ions $\cdot$ Combined effect $\cdot$ Mixture toxicity

\section{Introduction}

As a consequence of their small size, nanoparticles (NPs) possess physical and chemical features that are fundamentally different from their water-soluble or bulk counterparts. Those features include a high specific surface area, reactivity in

Responsible Editor: Philippe Garrigues

Rajdeep Roy

rajdeep@uni-landau.de

Mirco Bundschuh

bundschuh@uni-landau.de

1 iES Landau, Institute for Environmental Sciences, University of Koblenz-Landau, Fortstrasse 7, 76829 Landau, Germany

2 Department of Aquatic Sciences and Assessment, Swedish University of Agricultural Sciences, Uppsala, Sweden liquid or gas phase and rapid diffusion (Nowack and Bucheli 2007; Fan et al. 2011) making nanotechnology a multitrillion dollars business involving approximately 6 million employees worldwide (He et al. 2019). Furthermore, the Nanotechnology Consumer Products Inventory (CPI) listed 1814 consumer products from 6222 companies of 32 countries in 2015 (Mohajerani et al. 2019). This success goes along with an estimated annual production of NPs of approximately 300,000 metric tons in 2010. From this amount, 21\%, 17\% and $2.5 \%$ are assumed to be released at different stages of the nanoparticle's life cycle into water, soils and air, respectively (Keller et al. 2013; Keller and Lazareva 2014). In the environment, NPs interact with a range of natural (such as natural organic matter (NOM)) and anthropogenic substances including dissolved heavy metals that may represent a hazard for the integrity of freshwater ecosystems (Millennium Ecosystem 
Assessment 2005) raising concerns about their joint environmental health risk.

Indeed, some publications have reported increased metal toxicity in the presence of NPs (e.g. Fan et al. 2011; Wang et al. 2011; Rosenfeldt et al. 2014), while others highlight a reduction (Chen et al. 2015; Canesi et al. 2015). This remediation like effect may be explained by the adsorption of heavy metal ions onto the NPs surface, followed by an intraparticle diffusion, ultimately reducing heavy metal toxicity (Qu et al. 2013). The discrepancy of NP-induced changes in metal toxicity may depend on the NP concentration (Wang et al. 2011) as well as the metal identity or more specifically the metal ion's charge (Rosenfeldt et al. 2014). It was, moreover, highlighted that the combined toxicity of metals and NP depends on the environmental conditions triggering their fate and interaction over time (Rosenfeldt et al. 2016). Indeed, Rosenfeldt et al. (2016) highlighted that $\mathrm{Cu}$ toxicity was reduced with increasing aging duration in presence of titanium dioxide $\left(\mathrm{nTiO}_{2}\right)$ relative to NP's absence. While this pattern was observed in medium with ionic strength $(9.25 \mathrm{mmol} / \mathrm{L})$, distilled water (ionic strength $\sim 0 \mathrm{mmol} / \mathrm{L}$ ) did not influence $\mathrm{Cu}$ toxicity. The authors also documented that the presence of NOM could contribute to mitigation of $\mathrm{Cu}$ toxicity through complexation, an effect that is elevated in presence of $\mathrm{nTiO}_{2}$. At the same time, Seitz et al. (2015) documented that the presence of $\mathrm{NOM}$ during $\mathrm{nTiO}_{2}$ aging can slightly and transiently increase NP toxicity. These studies jointly suggest a complex interplay of NOM, NP and metal ions over time warranting further research targeting the temporal dynamics of this interaction and ultimately their consequence for aquatic biota.

In the present study, the consequences of $n \mathrm{TiO}_{2}$ aging $(0,1$, 3 and 6 days) at three concentrations (i.e. reflecting the $96 \mathrm{~h}$ $\mathrm{EC}_{10}$ and $\mathrm{EC}_{50}$ of $\mathrm{nTiO}_{2}$ (Fig. 1S) for Daphnia as well as the absence of $\mathrm{nTiO}_{2}$ ) in the presence and absence of NOM (seaweed extract as used in many earlier papers, namely Rosenfeldt et al. 2015a, 2016) on $\mathrm{Cu}$ toxicity (seven concentrations from the range $0-1536 \mu \mathrm{g} / \mathrm{L}$; using a spacing factor of 2) were assessed for the model species Daphnia magna. Thereby, two aging scenarios in ASTM reconstituted hard water (ASTM 2007) were realised prior to the toxicity assessment: the first scenario ensured the interaction of $\mathrm{nTiO}_{2}$ with $\mathrm{Cu}$ in presence and absence of NOM during aging. The second scenario focused on the aging of $\mathrm{nTiO}_{2}$ and NOM (presence vs. absence) with $\mathrm{Cu}$ being spiked to the test medium just before the introduction of the test species. These aging scenarios simulate the interaction of $\mathrm{Cu}$ with fresh $\mathrm{nTiO}_{2}$ (often in their nanoform) or with aged and thus agglomerated particles, whose average particle size is often in the $\mu \mathrm{m}$-range (Cupi et al. 2015; Seitz et al. 2015; Rosenfeldt et al. 2016), allowing to assess for the importance of the particle or agglomerate size. The selection of $\mathrm{nTiO}_{2}$ as model NP is motivated by its high production volume (Jovanović 2015) and widespread application (Baiqi et al. 2006; Chen and Mao 2007; Mueller and Nowack 2008). This NP has additionally only limited acute toxicity for Daphnia, which is even further reduced by NOM (Seitz et al. 2015). Copper (Cu) served as model heavy metal interfering with the sodium $\left(\mathrm{Na}^{+}\right)$regulation and metabolism in freshwater animals (Grosell and Wood 2002; Grosell et al. 2002), whose toxicity can also be reduced in presence of

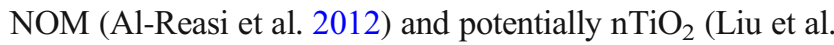
2015). Additionally, $\mathrm{Cu}$ has a broad application range, including agriculture leading to surface water levels in the high micrograms per litre range (Süß et al. 2006).

In the present study, it was hypothesised that (1) aging of $\mathrm{nTiO}_{2}$ along with $\mathrm{Cu}$ reduces $\mathrm{Cu}$ toxicity with increasing aging duration as a consequence of a reduced $\mathrm{Cu}$ bioavailability at test initiation (Rashidi et al. 2010). It was, moreover, assumed that (2) the aging of $\mathrm{nTiO}_{2}$ in the absence of $\mathrm{Cu}$ limits the NPs possibility to reduce effects of $\mathrm{Cu}$ when freshly added to the test medium just before toxicity testing. This is likely triggered by a lower surface area of NP agglomerates and the short interaction time before the test organisms experience $\mathrm{Cu}$ exposure (Aydin et al. 2008). Finally, it was presumed that (3) aging of $\mathrm{nTiO}_{2}$ in the presence of NOM reduces $\mathrm{Cu}$ toxicity with increasing aging duration. This pattern is triggered by NOM colloidally stabilising $\mathrm{nTiO}_{2}$ extending its interaction time with $\mathrm{Cu}$, ultimately reducing $\mathrm{Cu}$ effects (Lee et al. 2011). Moreover, NOM forms complexes with metal ions contributing to reduced $\mathrm{Cu}$ toxicity (Rosenfeldt et al. 2015a).

\section{Materials and methods}

\section{Chemicals}

A stable $\mathrm{nTiO}_{2}$ dispersion, produced by stirred media milling (PML 2; Bühler AG, Switzerland) of $\mathrm{P} 25 \mathrm{nTiO}_{2}$ powder (AEROXIDE® $\mathrm{TiO}_{2} \mathrm{P} 25$; advertised primary particle size of $21 \mathrm{~nm}$ and surface area of $50 \pm 15 \mathrm{~m}^{2} / \mathrm{g}$; Evonik) in deionised water, was provided by the Institute for Particle Technology (TU Braunschweig, Germany). The stock dispersion was stabilised at low $\mathrm{pH}(\sim 3)$, exhibiting a monodisperse size distribution and an average particle diameter of approximately $80 \mathrm{~nm}$ (Electronic supplementary material, Table 1S). The $\mathrm{nTiO}_{2}$ stock dispersion $(2000 \mathrm{mg} / \mathrm{L})$ was ultra-sonicated for $10 \mathrm{~min}$ prior use, to ensure a homogeneous particle distribution. The dissolved $\mathrm{Cu}$ stock solution was prepared separately for each experimental run using $\mathrm{Cu}\left(\mathrm{NO}_{3}\right)_{2} \times 3 \mathrm{H}_{2} \mathrm{O}$ (Carl Roth; purity $\geq 99 \%$, p.a., ACS). The salt was mixed with deionised water in a volumetric flask (polypropylene), followed by serial dilution to obtain the seven nominal test $\mathrm{Cu}$ concentrations ranging from 0 to $1536 \mu \mathrm{g} / \mathrm{L}$ (Tables $2 \mathrm{~S}$ and $3 \mathrm{~S}$ ). The exact concentration range depended on the aging scenario and was selected to obtain a full dose-response curve. Dissolved $\mathrm{Cu}$ species including $\mathrm{Cu}^{2+}, \mathrm{CuOH}^{+}$and 
$\mathrm{Cu}_{2}(\mathrm{OH})_{2}{ }^{2+}$ (Rosenfeldt et al. 2016) are hereafter summarised as $\mathrm{Cu}$.

\section{Test species}

The test species D. magna (clone V, Eurofins-GAB laboratories, Germany) was cultured in ASTM reconstituted hard water modified with selenium and vitamins (biotin, thiamine, cyanocobalamin) according to OECD 202 (OECD 2004) and $8 \mathrm{mg}$ TOC/L seaweed extract (Marinure ${ }^{\circ}$, Glenside, Scotland) (ASTM 2007). The culture medium was changed three times per week, and the organisms were fed with the green algae Desmodesmus sp. at an equivalent of $200 \mu \mathrm{g} \mathrm{C}$ per organism and day. The culture was maintained in a climate-controlled chamber (Weiss Environmental Technology Inc., Germany) at $20 \pm 1{ }^{\circ} \mathrm{C}$ and a $16: 8 \mathrm{~h}$ light:dark rhythm (800-1000 lx; OSRAM L 58 W/21-840 ECO, Germany). At the initiation of the bioassays, newly hatched juveniles (age $<24 \mathrm{~h}$ ) were collected and randomly introduced into the respective replicates using pasture pipette.

\section{Experimental setup}

The impact of $\mathrm{nTiO}_{2}$ on the toxicity of $\mathrm{Cu}$ was assessed under two aging scenarios involving a 3 -factorial $(2 \times 3 \times 7)$ experimental design each (Fig. 1). The aging procedures were performed due to space limitations at $16 \pm 1{ }^{\circ} \mathrm{C}$ and thus at a lower temperature relative to the toxicity bioassays (as the behaviour of $\mathrm{nTiO}_{2}$ was not impacted at the lower temperature (Table 4S), this was considered acceptable), in darkness on a horizontal shaker (50 rpm; VKS-B-50, Edmund Bühler $\mathrm{GmbH}$, Germany). The conditions during aging should prevent photo-activation of $\mathrm{nTiO}_{2}$ and consequently the oxidation of NOM (Seitz et al. 2015). Moreover, the constant shaking avoided sedimentation of $\mathrm{nTiO}_{2}$ and thereby ensured its constant availability in the water phase to interact with $\mathrm{NOM}$ and $\mathrm{Cu}$. In contrast to Rosenfeldt et al. (2016), who aged $\mathrm{Cu}, \mathrm{nTiO}_{2}$ and NOM as stock solutions, we performed aging in test medium (ASTM) (Table 5S) at nutrient, $\mathrm{Cu}$, $\mathrm{nTiO}_{2}$ and NOM concentrations as applied during toxicity testing, which avoided any impact of changes in the environmental conditions on the fate of $\mathrm{Cu}$ or $\mathrm{nTiO}_{2}$. During the first scenario (type 1), $\mathrm{nTiO}_{2}$ was aged at three levels $(0.0,0.6$ and $3.0 \mathrm{mg} / \mathrm{L}$ ) along with $\mathrm{Cu}$ (seven concentrations from the range $0-1536 \mu \mathrm{g} / \mathrm{L}$; using a spacing factor of 2$)$ in combination with NOM (0 vs. $8 \mathrm{mg}$ TOC/L; Table 2S). After 0 ( $\sim 15 \mathrm{~min}), 1,3$ and 6 days of aging (Rosenfeldt et al. 2016), the medium (or dispersion of $\mathrm{nTiO}_{2}$ in combination with $\mathrm{Cu}$ and $\mathrm{NOM}$ ) was used for toxicity testing (see bioassays). The second scenario (type 2) aged $\mathrm{nTiO}_{2}$ at the same three concentrations in presence or absence of NOM ( $8 \mathrm{mg}$ TOC/L) for 0 ( 15 min), 1, 3 and 6 days. Subsequently, the aged medium was transferred to the respective replicates of the bioassay, followed by addition of the respective $\mathrm{Cu}$ concentration (Table $3 \mathrm{~S}$ ) and test organisms. Irrespective of the aging scenario, the aged medium was homogenised by stirring at $350 \mathrm{rpm}$ for $2 \mathrm{~min}$ before separation into replicates. Additionally, the mean hydrodynamic diameter of the NPs was determined (Table 6S) at the bioassay initiation using dynamic light scattering (DelsaNano C, Beckman Coulter, Germany).

The concentrations of $\mathrm{Cu}$ were expected to change during aging, with its magnitude depending on the concentration of $\mathrm{nTiO}_{2}$ and NOM (Fan et al. 2016). Consequently, $\mathrm{Cu}$ levels were analytically determined after aging at the start of the
$0,1,3$ \& 6 days aging in ASTM medium under shaking and in darkness
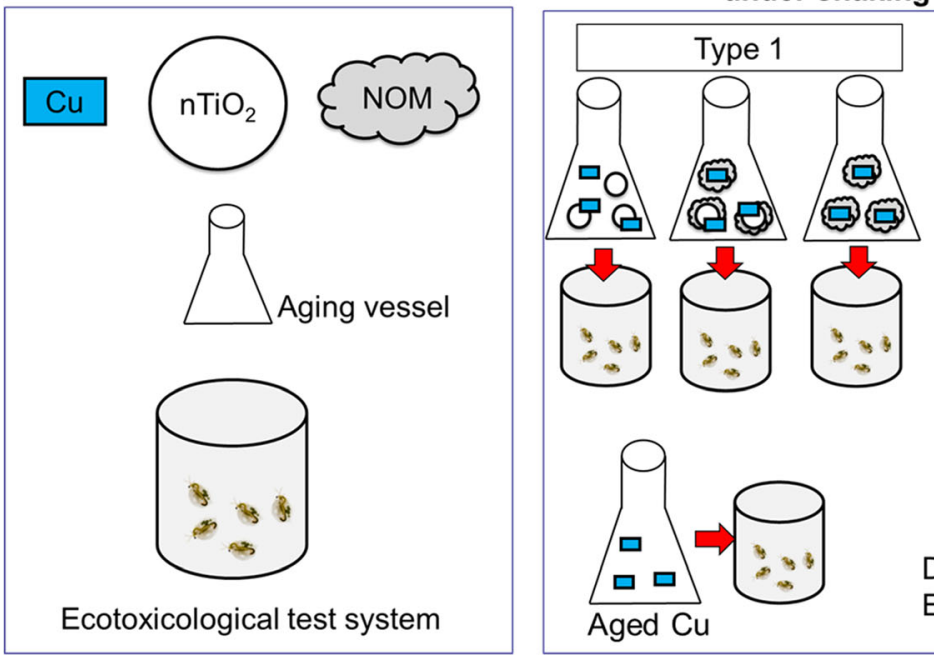

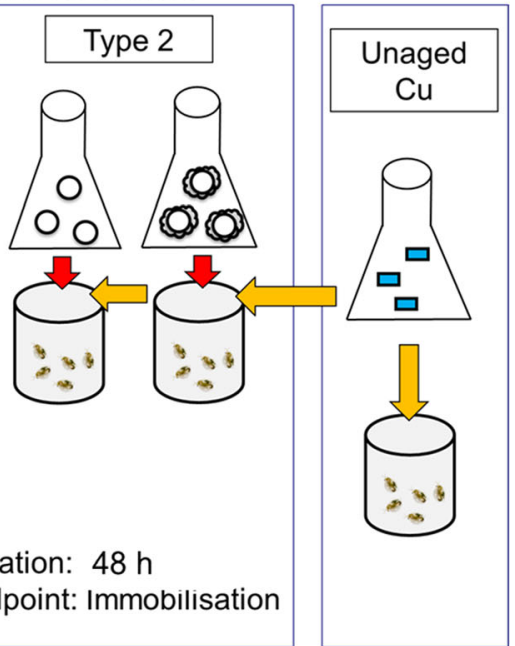

Endpoint: Immobilisation
Fig. 1 Schematic diagram visualizing the two aging scenarios (type 1 and type 2) assessing the impact of variable aging durations (i.e. 0, 1, 3 and 6 days) of $\mathrm{nTiO}_{2}$ in combination with NOM on the toxicity of co-aged or freshly added $\mathrm{Cu}$ towards $D$. magna. The test assessing for the sensitivity baseline of $D$. magna is also visualised (unaged $\mathrm{Cu}$ ) 
bioassays for the first aging scenario (type 1). As $\mathrm{Cu}$ was spiked to the aged medium just before the bioassay initiation for all experiments of the second scenario (type 2), accurate $\mathrm{Cu}$ spiking was anticipated based on the analytical results of the first aging scenario following 0 days of aging. Similarly, we quantified $\mathrm{nTiO}_{2}$ concentrations (Table 7S) only for one of the exposure scenarios ( 0 day aged samples) assuming a similar deviation between nominal and measured concentrations for other factor combinations. Quantification of $\mathrm{nTiO}_{2}$ and $\mathrm{Cu}$ at a later stage of the bioassays was not realised as the present study indicated that relevant interactions between $\mathrm{nTiO}_{2}$ and $\mathrm{Cu}$ occurred during the first hours (see Table 8S, "Results" and "Discussion").

The high number of acute toxicity tests required a temporal separation of the experiments, called experimental runs. To allow for a direct comparison of Daphnia responses among experimental runs, an additional dose-response experiment was performed during each experimental run quantifying the sensitivity of $D$. magna to unaged $\mathrm{Cu}$ (without $\mathrm{nTiO}_{2}$ and $\mathrm{NOM}$ ). The $\mathrm{EC}_{50}$ values obtained from these experiments were ultimately used as a sensitivity baseline allowing the quantification of changes in $\mathrm{Cu}$ toxicity depending on the aging conditions.

\section{Bioassays}

Per replicate, five juvenile daphnids $(<24 \mathrm{~h}$ age) were introduced into the aged ASTM medium containing respective concentrations of $\mathrm{nTiO}_{2}, \mathrm{Cu}$ and NOM and exposed for a duration of up to $96 \mathrm{~h}$. The immobilisation of Daphnia was recorded every $24 \mathrm{~h}$ (i.e. $24 \mathrm{~h}, 48 \mathrm{~h}, 72 \mathrm{~h}$ and $96 \mathrm{~h}$ ). The acute toxicity tests were performed in polystyrene beakers (filled with $50 \mathrm{~mL}$ of aged test medium) under controlled laboratory conditions $\left(20 \pm 1{ }^{\circ} \mathrm{C}\right.$ with a $16: 8 \mathrm{~h}$ light:dark rhythm) with four independent replicates per treatment, largely following OECD 202 (OECD 2004).

\section{Quantification of $\mathrm{nTiO}_{2}$ and $\mathrm{Cu}$}

The concentrations of $\mathrm{nTiO}_{2}$ or $\mathrm{Cu}$ in the aged medium were quantified according to the method described by Rosenfeldt et al. (2015b) with minor modification. Briefly, after aging (1, 3 and 6 days), $10 \mathrm{~mL}$ supernatant was taken from the water phase after centrifugation ( $4000 \mathrm{rpm}$ for $10 \mathrm{~min}$ ) of the aged medium. Centrifugation forced $\mathrm{nTiO}_{2}$ to sediment, ensuring the separation of $\mathrm{Cu}$ from NPs. The concentration of $\mathrm{Cu}$ adsorbed on the surface of $\mathrm{nTiO}_{2}$ was not analytically confirmed. After that, the samples were acidified with $\mathrm{HNO}_{3}$ $(65 \%)$ and stored at $4{ }^{\circ} \mathrm{C}$. However, in the case of 0 day aging, samples with $\mathrm{nTiO}_{2}$ were acidified with $\mathrm{HCl}(35 \%)$ to avoid agglomeration and analysed without centrifugation. The samples were analysed by Inductively Coupled Plasma Optical Emission Spectrometry (ICP-OES; Agilent 720, Germany) using the wavelengths of 336.12 and $327.39 \mathrm{~nm}$ for Ti and $\mathrm{Cu}$ quantification, respectively. The limit of detection was $2 \mu \mathrm{g} / \mathrm{L}$ for both $\mathrm{Ti}$ and $\mathrm{Cu}$. The measured concentration of $\mathrm{nTiO}_{2}$ (recalculated based on Ti quantification) deviated from their nominal levels by less than $20 \%$ justifying the use of the latter throughout the study (see Table 7S).

\section{Statistical analysis}

The statistical analyses of this study were performed with $\mathrm{R}$ version 3.0.1 (for windows) and the extension package drc (Ritz and Streibig 2005; R Core Team 2013). EC 50 values, the half median concentration causing immobilisation of $50 \%$ of daphnids, together with their $95 \%$ confidence interval were abstracted from dose-response models, while the model fitting the data best was selected by means of Akaike's information criterion (Tables 9S and 10S) and expert judgement. Model building was in a first-place based on nominal $\mathrm{Cu}$ concentrations (Figs. 2S-8S; Table 9S) and subsequently normalised to the effective (= measured) $\mathrm{Cu}$ concentration quantified in the water phase at bioassay initiation (Figs. 9S-15S; Tables $8 \mathrm{~S}$ and 10S). The latter step should aid data interpretation as to inform about negative effects on Daphnia, which may not be directly explainable by $\mathrm{Cu}$ water phase concentrations. All comparisons discussed in this paper are based on $48 \mathrm{~h} \mathrm{Cu}$ $\mathrm{EC}_{50}$ values, as effects caused by $\mathrm{Cu}$ after $24 \mathrm{~h}, 72 \mathrm{~h}$ and $96 \mathrm{~h}$ of exposure were either low $(24 \mathrm{~h})$ or already disguised by $\mathrm{nTiO}_{2}$ toxicity ( $72 \mathrm{~h}$ and $96 \mathrm{~h}$ ) (Dabrunz et al. 2011). Models and model parameters are reported in the electronic supplementary material (Figs. 2S-15S; Tables 9S and 10S). The $\mathrm{EC}_{50}$ values of each aging situation were evaluated for statistically significant differences as compared with the respective $\mathrm{EC}_{50}$ value of unaged $\mathrm{Cu}$ solution, as well as relative to the respective $\mathrm{EC}_{50}$ value of unaged ( 0 day aging) situation using $95 \%$ confidence interval testing (Wheeler et al. 2006). If 95\% CIs of the difference between two $\mathrm{EC}_{50}$ values did not include zero, the difference was considered statistically significant (Rosenfeldt et al. 2014).

\section{Results}

\section{Type 1 aging scenario}

Based on nominal $\mathrm{Cu}$ concentrations (Fig. 2), $3.0 \mathrm{mg} \mathrm{nTiO}_{2} / \mathrm{L}$ reduced $\mathrm{Cu}$ toxicity approx. 2-fold, relative to its absence, whereas $0.6 \mathrm{mg} \mathrm{nTiO}_{2} / \mathrm{L}$ did not change $\mathrm{Cu}$ toxicity after 0 , 1,3 and 6 days of aging. The presence of NOM significantly increased $\mathrm{EC}_{50}$ values independent of aging duration up to 2fold in the absence of $\mathrm{nTiO}_{2}$ relative to the unaged $\mathrm{Cu}$ treatment.

Adjusting the $\mathrm{Cu} \mathrm{EC}_{50}$ values to the $\mathrm{Cu}$ concentration, confirmed analytically in the water phase (Fig. 3), uncovered 
Fig. 2 Changes in the $\mathrm{Cu} 48 \mathrm{~h}$ $\mathrm{EC}_{50}$ of D. magna normalised to the toxicity induced by the unaged $\mathrm{Cu}$ solution (the reference 9.1 to $66.7 \pm 13.1 \mu \mathrm{g} / \mathrm{L}$ ) and reflect the impact of $\mathrm{nTiO}_{2}(0.0$, $8 \mathrm{mg} / \mathrm{L})$ and aging duration $(0,1$, 3,6 days) for the type 1 aging scenario. The $\mathrm{EC}_{50}$ values are based on nominal $\mathrm{Cu}$ concentrations. Asterisk indicates a significant difference of the respective $\mathrm{EC}_{50}$ value relative to the bioassays testing for the effects of unaged $\mathrm{Cu}$. The ' $\mathrm{a}$ ' indicates a significant difference of the respective $\mathrm{EC}_{50}$ values relative to the same combinations of treatments but aged for 0 days absolute $48 \mathrm{~h} \mathrm{EC}_{50}$ range $54.6 \pm$ 0.6 or $3.0 \mathrm{mg} / \mathrm{L}$ ), NOM (0 or

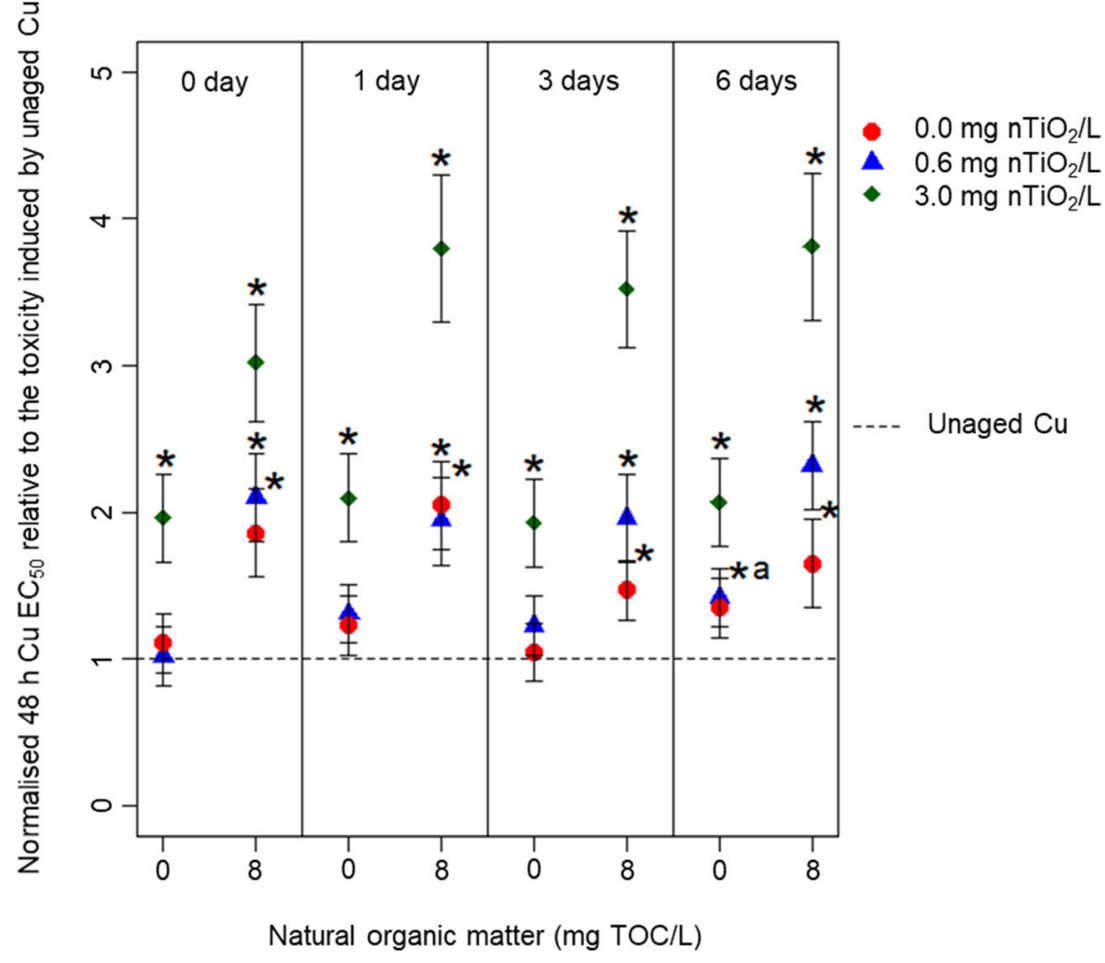

that in the absence of NOM at 0.0 and $0.6 \mathrm{mg} \mathrm{nTiO} / 2$, hardly any alteration occurred relative to the unaged $\mathrm{Cu}$ treatment. Contrary, the presence of $3.0 \mathrm{mg} \mathrm{nTiO}_{2} / \mathrm{L}$ initially $(0$ days of aging) led to a 2-fold reduction, but after 1, 3 and 6 days of aging, it turned into a 2 -fold increase in $\mathrm{Cu}$ toxicity. The amendment of NOM to the aging medium caused a reduction in $\mathrm{Cu}$ toxicity by $1.5-2$-fold at 0.0 and $0.6 \mathrm{mg} \mathrm{nTiO}_{2} / \mathrm{L}$, which was independent of the aging duration. In the presence of $3.0 \mathrm{mg} \mathrm{nTiO} / 2 / \mathrm{L}$ in combination with $8 \mathrm{mg} \mathrm{NOM} / \mathrm{L}$, in contrast, a reduction in $\mathrm{Cu}$ toxicity was observed reaching a factor
Fig. 3 Changes in the $\mathrm{Cu} 48 \mathrm{~h}$ $\mathrm{EC}_{50}$ of $D$. magna normalised to the toxicity induced by the unaged $\mathrm{Cu}$ solution (the reference absolute $48 \mathrm{~h} \mathrm{EC}_{50}$ range $47.9 \pm$ 8.0 to $58.6 \pm 11.5 \mu \mathrm{g} / \mathrm{L}$ ) and reflect the impact of $\mathrm{nTiO}_{2}(0.0$, 0.6 or $3.0 \mathrm{mg} / \mathrm{L})$, NOM ( 0 or $8 \mathrm{mg} / \mathrm{L})$ and aging duration $(0,1$, 3,6 days) for the type 1 aging scenario. The $\mathrm{EC}_{50}$ values are based on measured $\mathrm{Cu}$ concentrations. Asterisk indicates a significant difference of the respective $\mathrm{EC}_{50}$ value relative to the bioassays testing for the effects of unaged $\mathrm{Cu}$. The ' $\mathrm{a}$ ' indicates a significant difference of the respective $\mathrm{EC}_{50}$ values relative to the same combinations of treatments but aged for 0 days

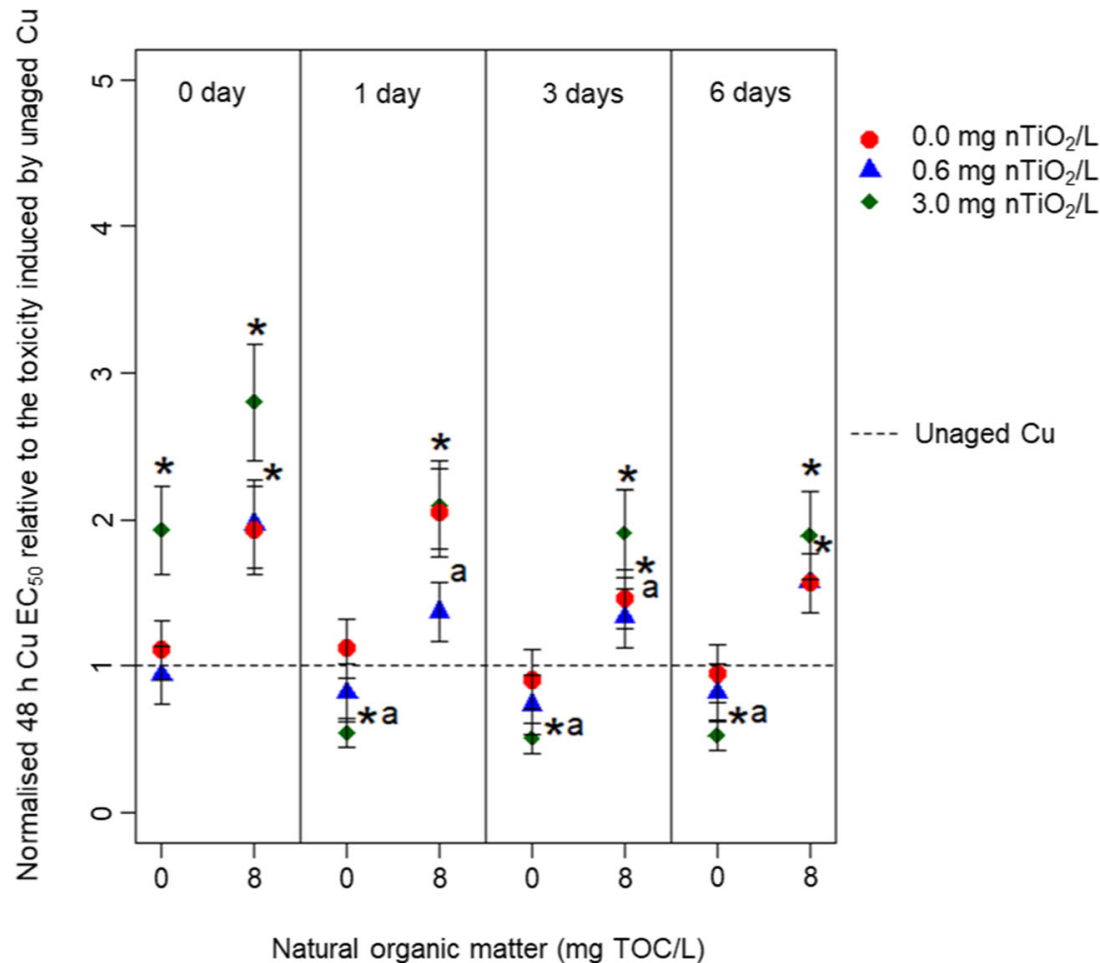


of up to three. This mitigation like effect continuously decreased to a factor of two, approaching $48 \mathrm{~h} \mathrm{EC}_{50}$ values comparable with 6 days of aging at 0.0 and $0.6 \mathrm{mg} \mathrm{nTiO}_{2} / \mathrm{L}$.

\section{Type 2 aging scenario}

Aging of $\mathrm{nTiO}_{2}$ with or without $\mathrm{NOM}$ before adding $\mathrm{Cu}$ and the test organisms (Fig. 4; see based on measured concentration in Fig. 16S) resulted in a similar pattern as discussed for the nominal concentrations when applying the type 1 aging scenario (Fig. 2). In general, while NOM reduced Cu toxicity, the low $\mathrm{nTiO}_{2}$ concentration had no additional mitigating effect neither in presence nor in the absence of NOM. Only at $3.0 \mathrm{mg} \mathrm{nTiO} / 2 / \mathrm{L}$, a further reduction in $\mathrm{Cu}$ toxicity was observed. These patterns were independent of the aging duration.

\section{Discussion}

\section{Influence of $\mathrm{nTiO}_{2}$ on $\mathrm{Cu}$ toxicity in the absence of NOM}

The changes in $\mathrm{Cu}$-induced toxicity in presences of $\mathrm{nTiO}_{2}$ is likely triggered by the NP's negative surface charge (approx. $-9 \mathrm{mV}$ in absence of NOM as documented by (Rosenfeldt et al. 2015a) attracting positively charged $\mathrm{Cu}$ species (e.g. $\mathrm{Cu}^{2+}, \mathrm{CuOH}^{+}, \mathrm{Cu}_{2}(\mathrm{OH})_{2}{ }^{2+}$ ) (Rosenfeldt et al. 2016). Although the present study does not address the underlying chemical mechanisms of the observations reported here, it clearly displays that the concentration of $\mathrm{nTiO}_{2}$ is an important driver influencing $\mathrm{Cu}$ toxicity. At $0.6 \mathrm{mg} \mathrm{nTiO} / 2 / \mathrm{L}$, there was hardly any difference in $\mathrm{Cu}$ toxicity relative to the NP's absence. The presence of $3.0 \mathrm{mg} \mathrm{nTiO} / 2 / \mathrm{L}$, in contrast, caused substantial changes in $\mathrm{Cu}$-induced toxicity. Besides the NP concentration, also the particle size, an indicator for the available surface area, might trigger the magnitude of changes in $\mathrm{Cu}$ toxicity (Rosenfeldt et al. 2015a). As the particle size was comparable at the start as well as at the termination of the aging procedure among the two applied NP concentrations (Table 6S), the latter determines the surface area available for interactions with $\mathrm{Cu}$ and thus not the particle size. Consequently, the lower $\mathrm{nTiO}_{2}$ concentration provided insufficient surface area to reduce $\mathrm{Cu}$ concentrations in the water phase (Table 8S) and, thus, its effects in Daphnia. The type 2 aging scenario supports this interpretation, namely that the concentration of $\mathrm{nTiO}_{2}$ is the main driver in the present study for the observed effects: We aged $\mathrm{nTiO}_{2}$ in the absence of $\mathrm{Cu}$, which increased its particle size (Table 6S), before interacting with $\mathrm{Cu}$. The mitigation potential of $\mathrm{nTiO}_{2}$ for $\mathrm{Cu}$-induced toxicity did not substantially change with increasing aging duration and thus particles size, while the observed effects were comparable among aging scenarios (Figs. 2 and 4). Moreover, the interaction between $\mathrm{Cu}$ and $\mathrm{nTiO}_{2}$ seems to be a rapid process highlighted by the reduction in $\mathrm{Cu}$ toxicity independent of the aging scenario and aging duration. However, as the $\mathrm{Cu}$ concentration was only quantified at the start of the Daphnia bioassay but not during the actual
Fig. 4 Changes in the $\mathrm{Cu} 48 \mathrm{~h}$ $\mathrm{EC}_{50}$ of D. magna normalised to the toxicity induced by the unaged $\mathrm{Cu}$ solution (the reference absolute $48 \mathrm{~h} \mathrm{EC}_{50}$ range $54.6 \pm$ 9.1 to $59.7 \pm 2.0 \mu \mathrm{g} / \mathrm{L}$ ) and reflect the impact of $\mathrm{nTiO}_{2}(0.0,0.6$ or $3.0 \mathrm{mg} / \mathrm{L}$ ), NOM (0 or $8 \mathrm{mg} / \mathrm{L}$ ) and aging duration $(0,1,3$, 6 days) for the type 2 aging scenario. The $\mathrm{EC}_{50}$ values are based on nominal $\mathrm{Cu}$ concentrations. Asterisk indicates a significant difference of the respective $\mathrm{EC}_{50}$ value relative to the bioassays testing for the effects of unaged $\mathrm{Cu}$. The ' $\mathrm{a}$ ' indicates a significant difference of the respective $\mathrm{EC}_{50}$ values relative to the same combinations of treatments but aged for 0 days

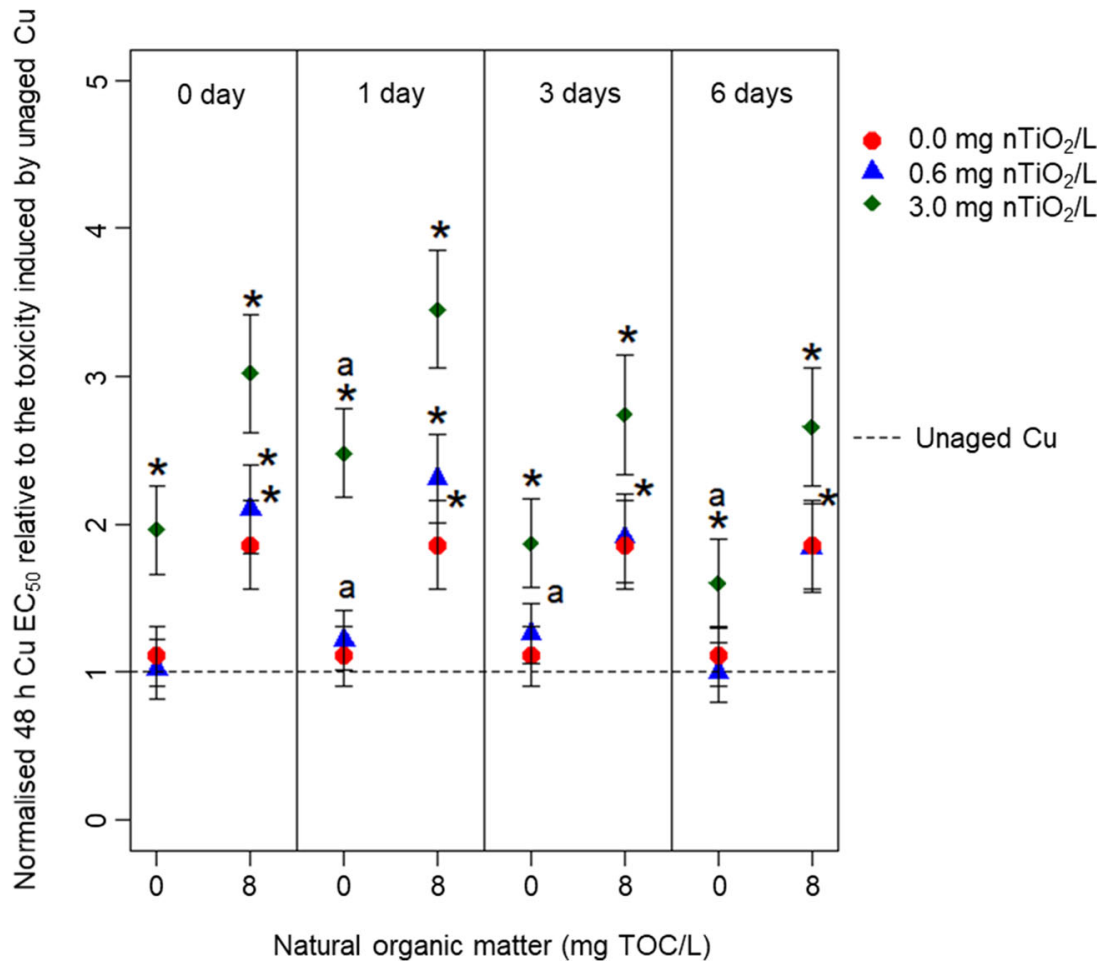


bioassay, this requires further evaluation. Conjointly, the first and second hypotheses suggesting an impact of aging time and agglomeration size of $\mathrm{nTiO}_{2}$ for $\mathrm{Cu}$ mitigation need to be rejected.

As indicated above, the direction of $\mathrm{Cu}$ toxicity changed (i.e. increased) when based on its analytically verified concentration at the start of the experiment with $D$. magna, relative to its nominal concentration in the presence of $3.0 \mathrm{mg} \mathrm{nTiO}_{2} / \mathrm{L}$ under the type 1 aging scenario. As the $\mathrm{nTiO}_{2}$ concentration tested here did not induce any mortality after comparable exposure durations when tested individually (Fig. 1S), these differences point to additional exposure pathways relative to the waterborne exposure alone. In other words, if the $\mathrm{Cu}$ water phase concentration would explain the observed toxicity, the $\mathrm{Cu} \mathrm{EC}_{50}$ value should be comparable with those obtained in the absence of $\mathrm{NOM}$ and $\mathrm{nTiO}_{2}$ and without aging (baseline $\mathrm{Cu}$ toxicity experiments). This pattern would have remained unnoticed when the assessment is based exclusively on $\mathrm{Cu}$ concentrations confirmed before aging - in fact, the $\mathrm{Cu}$ concentration measured in the water phase would lead to an underestimation of acute effects. As additional exposure pathway, Daphnia may have ingested NPs together with $\mathrm{Cu}$. During gut passage (at $\mathrm{pH}=$ neutral), $\mathrm{Cu}$ may have been remobilised as a consequence of enzyme (including protease, amylase, lipase and cellulase) activity (Weltens et al. 2000; Rosenfeldt et al. 2014). Ultimately, this pathway interacts with the waterborne $\mathrm{Cu}$ exposure explaining the increased toxicity when based on measured concentrations (Fig. 3).

\section{Influence of NOM on Cu toxicity}

The reduction in $\mathrm{Cu}$ induced toxicity in the presence of $\mathrm{NOM}$ and independent of the aging scenario or duration can mainly be explained by the formation of $\mathrm{Cu}$ chelates. These $\mathrm{Cu}$ chelates are formed through the interaction with carboxylic and phenolic groups of NOM, ultimately reducing the bioavailability of $\mathrm{Cu}$ (Lorenzo et al. 2002; Rosenfeldt et al. 2015a; $\mathrm{Yu}$ et al. 2018). In the presence of $\mathrm{nTiO}_{2}$, NOM further decreased the toxicity triggered by $\mathrm{Cu}$ (Figs. 2 and 4). This pattern, which is in line with our third hypothesis, may be driven by a coating of the NP's surface (Fig. 17S) with hydrophobic or aromatic components of the NOM (Lee et al. 2011; Pakarinen et al. 2013). This process is, on the one hand, known to reduce agglomeration and thus stabilises $\mathrm{nTiO}_{2}$ (see Table 6S) through electrostatic repulsion in the water phase (Loosli et al. 2014). Thereby, the available surface area for $\mathrm{Cu}$ adsorption is increased relative to the absence of NOM. Moreover, the presence of hydrophobic or aromatic organic material on $\mathrm{nTiO}_{2}$ surfaces further enhances the surface charge (from approx. $-9 \mathrm{mV}$ in absence to $-20 \mathrm{mV}$ in presence of NOM, respectively, as documented by Rosenfeldt et al. 2015a), which may have stimulated $\mathrm{Cu}$ adsorption and complexation. Those processes, however, in combination with the direct interaction of $\mathrm{Cu}$ and NOM in the water phase, might have contributed to the observed decrease in $\mathrm{Cu}$ toxicity. This assumption is also supported when comparing the $\mathrm{EC}_{50}$ values based on measured and nominal $\mathrm{Cu}$ concentrations during the type 1 aging scenario (Figs. 2 and 3). The fact that the $\mathrm{EC}_{50}$ valuesparticularly after aging in the presence of the high $\mathrm{nTiO}_{2}$ concentration - are substantially reduced when based on measured relative to nominal concentrations (Figs. 2 and 3) points towards the significant $\mathrm{Cu}$ adsorption onto NOM coated $\mathrm{nTiO}_{2}$. Furthermore, the $\mathrm{EC}_{50}$ values based on measured $\mathrm{Cu}$ concentrations in the presence of NOM were higher relative to the absence of both $\mathrm{NOM}$ and $\mathrm{nTiO}_{2}$. This outcome suggests that $\mathrm{Cu}$ complexation is reducing its toxicity by roughly $50 \%$ (Fig. 3).

Nonetheless, the uptake of $\mathrm{Cu}$ complexed by NOM on $\mathrm{nTiO}_{2}$ surfaces is possible in Daphnia considering their particle size distribution (Table 6S) exceeds the mesh size (240$640 \mathrm{~nm}$ ) of Daphnia's filtering apparatus (Seitz et al. 2015). However, the $\mathrm{Cu}$ on the NP's surface seems to be less bioavailable in presence relative to the absence of NOM (Figs. 2 and 3 ) as the $\mathrm{EC}_{50}$ value based on measured $\mathrm{Cu}$ concentrations indicated a reduced toxicity in the presence of NOM relative to the elevated toxicity in the absence of NOM.

In conclusion, from the present study, it is evident that field relevant concentrations of $\mathrm{nTiO}_{2}$, namely far below the lowest concentration of $0.6 \mathrm{mg} / \mathrm{L}$ as tested here, are unlikely to influence $\mathrm{Cu}$ toxicity significantly. Despite a trend to an increased $\mathrm{Cu}$ toxicity is observed in the presence of $0.6 \mathrm{mg} \mathrm{nTiO} / / \mathrm{L}$ but absence of NOM, this assumption seems reasonable particularly as in surface water bodies, NOM is ubiquitous, which triggered a reduction in $\mathrm{Cu}$ toxicity in our study. Moreover, we can see that the aging duration does not meaningfully affect the direction and magnitude of $\mathrm{Cu}$ induced effects pointing to a rapid interaction between $\mathrm{NOM}, \mathrm{Cu}$ and $\mathrm{nTiO}_{2}$. This rapid interaction also suggests that changes in $\mathrm{Cu}$ toxicity in the long run, are rather unlikely - at least under stable environmental conditions as tested here. Nonetheless, the present study highlights the possibility of NPs to increase toxicity if $\mathrm{Cu}$ is taken up during gut passage, a pathway of exposure largely overlooked in the assessment of combined effects of particulate stressors (nanoparticles or nanoplastics) and dissolved chemical stressors. Additionally, the direct effects of $\mathrm{nTiO}_{2}$ seems of little relevance for the actual toxicity assessment as the toxicity of the NPs tested in the present study only appeared after $96 \mathrm{~h}$ of exposure. Finally, it is suggested to assess for the transferability of the results generated here to other heavy metals (with variable ionic charge) to allow for a general interpretation of the relevance of this process. 
Supplementary Information The online version contains supplementary material available at https://doi.org/10.1007/s11356-020-11578-2.

Acknowledgements The authors acknowledge Therese Bürgi for support in the laboratory, Wolfgang Fey for ICP-OES analysis, Allan Philippe for SEM-EDX analysis and Carsten Schilde for providing the $\mathrm{nTiO}_{2}$ dispersion. The authors also acknowledge Jochen P. Zubrod, Ricki R. Rosenfeldt and Frank Seitz for their support in various aspects of this study.

Authors' contributions $\mathrm{MB}$ and $\mathrm{RR}$ designed the experiments. RR, AAAM and SL performed the experiments. RR, AAAM, MB, SL, GM and RS analysed the data. MB and RR wrote the manuscript.

Funding Open Access funding enabled and organized by Projekt DEAL. German Research Foundation (Grant No. SCHU2271/5-1), German Academic Exchange Service (Grant No. 57299294) and European Fund for regional development (EFRE/FEDER).

Data availability All data generated or analysed during this study are included in this published research article and its electronic supplementary material.

\section{Compliance with ethical standards}

Ethical approval Not applicable.

Consent to participate Not applicable.

Consent to publish Not applicable.

Competing interests One of the authors (RS) is managing director of a small consultancy working in the field of ecotoxicology and environmental risk assessment, while another co-author (SL) is now working in the private sector, namely the chemical industry. The authors, however, do not feel a conflict of interest as a consequence of this situation.

Open Access This article is licensed under a Creative Commons Attribution 4.0 International License, which permits use, sharing, adaptation, distribution and reproduction in any medium or format, as long as you give appropriate credit to the original author(s) and the source, provide a link to the Creative Commons licence, and indicate if changes were made. The images or other third party material in this article are included in the article's Creative Commons licence, unless indicated otherwise in a credit line to the material. If material is not included in the article's Creative Commons licence and your intended use is not permitted by statutory regulation or exceeds the permitted use, you will need to obtain permission directly from the copyright holder. To view a copy of this licence, visit http://creativecommons.org/licenses/by/4.0/.

\section{References}

Al-Reasi HA, Scott Smith D, Wood CM (2012) Evaluating the ameliorative effect of natural dissolved organic matter (DOM) quality on copper toxicity to Daphnia magna: improving the BLM. Ecotoxicology 21:524-537. https://doi.org/10.1007/s10646-011$0813-\mathrm{z}$

ASTM (2007) E729-96 standard guide for conducting acute toxicity tests on test materials with fishes, macroinvertebrates and amphibians.
ASTM International, West Conshohocken, PA, 2007, www.astm.org

Aydın H, Bulut Y, Yerlikaya Ç (2008) Removal of copper (II) from aqueous solution by adsorption onto low-cost adsorbents. J Environ Manag 87:37-45. https://doi.org/10.1016/j.jenvman.2007. 01.005

Baiqi W, Liqiang J, Yichun Q, Shudan L, Baojiang J, Libin Y, Baifu X, Honggang F (2006) Enhancement of the photocatalytic activity of $\mathrm{TiO}_{2}$ nanoparticles by surface-capping DBS groups. Appl Surf Sci 252:2817-2825. https://doi.org/10.1016/j.apsusc.2005.04.025

Canesi L, Ciacci C, Balbi T (2015) Interactive effects of nanoparticles with other contaminants in aquatic organisms: friend or foe? Mar Environ Res 111:128-134. https://doi.org/10.1016/j.marenvres. 2015.03.010

Chen X, Mao SS (2007) Titanium dioxide nanomaterials: synthesis, properties, modifications, and applications. Chem Rev 107:2891-2959. https://doi.org/10.1021/cr0500535

Chen J, Qian Y, Li H, Cheng Y, Zhao M (2015) The reduced bioavailability of copper by nano- $\mathrm{TiO}_{2}$ attenuates the toxicity to Microcystis aeruginosa. Environ Sci Pollut Res 22:12407-12414. https://doi. org/10.1007/s11356-015-4492-9

Cupi D, Hartmann NB, Baun A (2015) The influence of natural organic matter and aging on suspension stability in guideline toxicity testing of silver, zinc oxide, and titanium dioxide nanoparticles with Daphnia magna: natural organic matter and aging on nanoparticle. Environ Toxicol Chem 34:497-506. https://doi.org/10.1002/etc. 2855

Dabrunz A, Duester L, Prasse C, Seitz F, Rosenfeldt R, Schilde C, Schaumann GE, Schulz R (2011) Biological surface coating and molting inhibition as mechanisms of $\mathrm{TiO}_{2}$ nanoparticle toxicity in Daphnia magna. PLoS One 6:e20112. https://doi.org/10.1371/ journal.pone.0020112

Fan W, Cui M, Liu H, Wang C, Shi Z, Tan C, Yang X (2011) Nano-TiO enhances the toxicity of copper in natural water to Daphnia magna. Environ Pollut 159:729-734. https://doi.org/10.1016/j.envpol.2010. 11.030

Fan W, Peng R, Li X, Ren J, Liu T, Wang X (2016) Effect of titanium dioxide nanoparticles on copper toxicity to Daphnia magna in water: role of organic matter. Water Res 105:129-137. https://doi.org/ 10.1016/j.watres.2016.08.060

Grosell M, Wood CM (2002) Copper uptake across rainbow trout gills. J Exp Biol 205:1179

Grosell M, Nielsen C, Bianchini A (2002) Sodium turnover rate determines sensitivity to acute copper and silver exposure in freshwater animals. Comp Biochem Physiol C Toxicol Pharmacol 133:287303. https://doi.org/10.1016/S1532-0456(02)00085-6

He X, Deng H, Hwang H (2019) The current application of nanotechnology in food and agriculture. J Food Drug Anal 27:1-21. https://doi. org/10.1016/j.jfda.2018.12.002

Jovanović B (2015) Review of titanium dioxide nanoparticle phototoxicity: developing a phototoxicity ratio to correct the endpoint values of toxicity tests: $\mathrm{TiO}_{2}$ nanoparticles phototoxicity. Environ Toxicol Chem 34:1070-1077. https://doi.org/10.1002/etc.2891

Keller AA, Lazareva A (2014) Predicted releases of engineered nanomaterials: from global to regional to local. Environ Sci Technol Lett 1:65-70. https://doi.org/10.1021/ez400106t

Keller AA, McFerran S, Lazareva A, Suh S (2013) Global life cycle releases of engineered nanomaterials. J Nanopart Res 15:1692. https://doi.org/10.1007/s11051-013-1692-4

Lee S, Kim K, Shon HK, Kim SD, Cho J (2011) Biotoxicity of nanoparticles: effect of natural organic matter. J Nanopart Res 13:30513061. https://doi.org/10.1007/s11051-010-0204-z

Liu L, Fan W, Lu H, Xiao W (2015) Effects of the interaction between $\mathrm{TiO}_{2}$ with different percentages of exposed $\{001\}$ facets and $\mathrm{Cu}^{2+}$ on biotoxicity in Daphnia magna. Sci Rep 5:11121. https://doi.org/ $10.1038 /$ srep11121 
Loosli F, Le Coustumer P, Stoll S (2014) Effect of natural organic matter on the disagglomeration of manufactured $\mathrm{TiO}_{2}$ nanoparticles. Environ Sci Nano 1:154. https://doi.org/10.1039/c3en00061c

Lorenzo JI, Nieto O, Beiras R (2002) Effect of humic acids on speciation and toxicity of copper to Paracentrotus lividus larvae in seawater. Aquat Toxicol 58:27-41. https://doi.org/10.1016/S0166-445X(01) 00219-3

Millennium Ecosystem Assessment (2005) Ecosystems and human wellbeing: opportunities and challenges for business and industry. World Resources Institute, Washington, DC

Mohajerani, Burnett, Smith et al (2019) Nanoparticles in construction materials and other applications, and implications of nanoparticle use. Materials 12:3052. https://doi.org/10.3390/ma12193052

Mueller NC, Nowack B (2008) Exposure modeling of engineered nanoparticles in the environment. Environ Sci Technol 42:4447-4453. https://doi.org/10.1021/es7029637

Nowack B, Bucheli TD (2007) Occurrence, behavior and effects of nanoparticles in the environment. Environ Pollut 150:5-22. https://doi. org/10.1016/j.envpol.2007.06.006

OECD (2004) Test No. 202: Daphnia sp. Acute Immobilisation Test, OECD Guidelines for the Testing of Chemicals, Section 2, OECD Publishing, Paris.

Pakarinen K, Petersen EJ, Alvila L, Waissi-Leinonen GC, Akkanen J, Leppänen MT, Kukkonen JVK (2013) A screening study on the fate of fullerenes $\left(\mathrm{nC}_{60}\right)$ and their toxic implications in natural freshwaters: Fate and toxicity of $\mathrm{nC}_{60}$ by varying water characters. Environ Toxicol Chem 32:1224-1232. https://doi.org/10.1002/etc.2175

Qu X, Alvarez PJJ, Li Q (2013) Applications of nanotechnology in water and wastewater treatment. Water Res 47:3931-3946. https://doi.org/ 10.1016/j.watres.2012.09.058

R Core Team (2013) R: a language and environment for statistical computing. 3.0.1 ed. R Foundation for Statistical Computing, Vienna

Rashidi F, Sarabi RS, Ghasemi Z, Seif A (2010) Kinetic, equilibrium and thermodynamic studies for the removal of lead (II) and copper (II) ions from aqueous solutions by nanocrystalline. Superlattice Microst 48:577-591. https://doi.org/10.1016/j.spmi.2010.09.011

Ritz C, Streibig JC (2005) Bioassay analysis using $R$. J Stat Softw 12. https://doi.org/10.18637/jss.v012.i05

Rosenfeldt RR, Seitz F, Schulz R, Bundschuh M (2014) Heavy metal uptake and toxicity in the presence of titanium dioxide nanoparticles: a factorial approach using Daphnia magna. Environ Sci Technol 48:6965-6972. https://doi.org/10.1021/es405396a
Rosenfeldt RR, Seitz F, Senn L, Schilde C, Schulz R, Bundschuh M (2015a) Nanosized titanium dioxide reduces copper toxicity - the role of organic material and the crystalline phase. Environ Sci Technol 49:1815-1822. https://doi.org/10.1021/es506243d

Rosenfeldt RR, Seitz F, Zubrod JP, Feckler A, Merkel T, Lüderwald S, Bundschuh R, Schulz R, Bundschuh M (2015b) Does the presence of titanium dioxide nanoparticles reduce copper toxicity? A factorial approach with the benthic amphipod Gammarus fossarum. Aquat Toxicol 165:154-159. https://doi.org/10.1016/j.aquatox.2015.05. 011

Rosenfeldt RR, Seitz F, Haigis A-C, Höger J, Zubrod JP, Schulz R, Bundschuh M (2016) Nanosized titanium dioxide influences copper-induced toxicity during aging as a function of environmental conditions: toxicity of copper and nanosized $\mathrm{TiO}_{2}$ - the effect of aging. Environ Toxicol Chem 35:1766-1774. https://doi.org/10. 1002/etc. 3325

Seitz F, Lüderwald S, Rosenfeldt RR, Schulz R, Bundschuh M (2015) Aging of $\mathrm{TiO}_{2}$ nanoparticles transiently increases their toxicity to the pelagic microcrustacean Daphnia magna. PLoS One 10: e0126021. https://doi.org/10.1371/journal.pone.0126021

Süß A, Bischoff G, Mueller ACW, Buhr L (2006) Chemisch-biologisches Monitoring zu Pflanzenschutzmittel- belastungen und Lebensgemeinschaften in Gräben des Alten Landes. Nachrichtenblatt des Deutschen Pflanzenschutzdienstes 58:28-42

Wang D, Hu J, Irons DR, Wang J (2011) Synergistic toxic effect of nano$\mathrm{TiO}_{2}$ and $\mathrm{As}(\mathrm{V})$ on Ceriodaphnia dubia. Sci Total Environ 409: 1351-1356. https://doi.org/10.1016/j.scitotenv.2010.12.024

Weltens R, Goossens R, Van Puymbr S (2000) Ecotoxicity of contaminated suspended solids for filter feeders (Daphnia magna). Arch Environ Contam Toxicol 39:315-323. https://doi.org/10.1007/ s002440010110

Wheeler MW, Park RM, Bailer AJ (2006) Comparing median lethal concentration values using confidence interval overlap or ratio tests. Environ Toxicol Chem 25:1441. https://doi.org/10.1897/05-320R.1

Yu S, Liu J, Yin Y, Shen M (2018) Interactions between engineered nanoparticles and dissolved organic matter: a review on mechanisms and environmental effects. J Environ Sci 63:198-217. https://doi. org/10.1016/j.jes.2017.06.021

Publisher's note Springer Nature remains neutral with regard to jurisdictional claims in published maps and institutional affiliations. 